\title{
Melatonin Induces Cell Cycle Arrest, Inhibits Cell Proliferation and Accelerates Apoptosis by Modulation of CDK4 in NSCLC
}

\section{Mengxi Zhou ( $\sim$ zhoumx1992@163.com )}

First Affiliated Hospital of Anhui Medical University https://orcid.org/0000-0001-7940-1795

\section{Yueguo Wang}

First Affiliated Hospital of Anhui Medical University

Jilong Shen

Anhui Medical University

\section{Guanghe Fei}

First Affiliated Hospital of Anhui Medical University https://orcid.org/0000-0003-0064-2073

\section{Research Article}

Keywords: melatonin, CDK4, cell cycle arrest, NSCLC

Posted Date: January 10th, 2022

DOI: https://doi.org/10.21203/rs.3.rs-1230442/v1

License: (a) (i) This work is licensed under a Creative Commons Attribution 4.0 International License. Read Full License 


\section{Abstract \\ Purpose}

To explore whether melatonin affect the progression of cell cycle and exert anticancer activities via the modulation of CDK4 in NSCLC .

\section{Methods}

Cells treated with melatonin were used for assessing the anticancer effect of melatonin. Cells transfected with lentivirus for CDK4 upregulation or downregulation was constructed to evaluate the role of CDK4 in melatonin-induced anticancer effect. The protein and mRNA level of CDK4, PCNA and Bax were detected by western blotting and qRT-PCR. The application of flow cytometry was used for analyzing the distribution of cell cycle and apoptosis. Animal model of subcutaneous tumor was constructed and used for further study in vivo.

\section{Results}

We found that melatonin inhibited cell viability, colony formation, downregulated the expression of CDK4 and PCNA while upregulated the level of Bax. Besides, melatonin decreased the phosphorylation of ERK. Importantly, inhibition of ERK activation by PD98059 particapated in melatonin-induced downregulation of CDK4. Furthermore, melatonin led to G1 arrest and cell apoptosis. CDK4 knockdown enhanced melatonin-induced cell cycle arrest while CDK4 overexpression reversed the effect. Additionally, the animal experiment showed that melatonin decreased the level of CDK4 and inhibited tumor growth. However, the anti-tumor effect of melatonin was reversed by CDK4 overexpression.

\section{Conclusion}

Taken together, CDK4 involved in anti-cancer activities of melatonin. Melatonin led to G1 arrest, blocked G1-to-S transition, as a result, inhibited cell proliferation and accelerates apoptosis via suppressing CDK4 signaling. Targeting CDK4 inhibition and combining it with melatonin has protential to be a novel strategy for NSCLC.

\section{Introduction}

According to the statistics published by world Health Organization in 2020, there were more than 2 million new cases $(11.4 \%)$ and 1.8 million death cases of lung cancer, which has remained highest death rate of cancer (Sung et al., 2020). Non-small cell lung cancer (NSCLC) occupies around $85 \%$, and has been recognized highly aggressive and prevalent (Lee et al., 2019). Although there are many advanced 
methods, patients with NSCLC are suffering from poor prognosis, for it's five-year overall survival rate is no more than $16 \%$ (Chen et al., 2014).

Melatonin is mainly secreted by pineal gland of mammals and humans. Melatonin production is activated in the darkness while inhibited in the light. It is well-known that melatonin is vital in participating in biological rhythms, especially in regulating circadian rhythm (Ma et al., 2019; Pourhanifeh et al., 2019; Hardeland et al., 2011). Lack of melatonin may result in physiological disorders, such as heart disease, hypertension, depression, sleep disorders (Tan et al., 2015). Moreover, night shift work and disruption of melatonin secretion may increase the risk of cancers (Papantonious et al., 2016;

Sigurdardottir et al., 2015). Women lack of melatonin secretion were found to possess higher risk of breast cancer (Devore et al., 2017; Basler et al., 2014). Emerging researches provided that melatonin has oncostatic properties in several cancers (Jablonska et al., 2013; Hevia et al., 2015; Plaimee et al., 2015). However, the underlying mechanisms of melatonin on NSCLC hasn't been fully elucidated yet.

Carcinogenesis is closely related to cell cycle dysregulation. CDKs, a variety of cyclin-dependent kinases, activate alternately along the cell cycle process. Among them, CDK4 mainly participated in the transition from G1-to-S phase (Kong et al., 2019). It is reported that tumorigenesis associated with mutation, deletion and silence of P16, an inner CDK4 inhibitor (Thangavel et al., 2018). Thus, CDK4 dysfunction may led to higher risk of tumorigenesis. CDK4 was verified to expressed more in human lung cancer tissues than in normal tissue (Feng et al., 2019). CDK4 inhibition specifically blocks G1-to-S transition, decelerates cell division and accelerates cell apoptosis (Hydbring et al., 2016; Sobhani et al., 2019).

Herein, we found CDK4 downregulation involved in anticancer activities of melatonin. Melatonin function as a CDK4 suppressor, induced G1 phase arrest, blocked G1-to-S transition, as a result, inhibited cell proliferation and accelerated apoptosis. Hence, CDK4 inhibition in combination with melatonin may be a novel strategy for NSCLC.

\section{Materials And Methods \\ 2.1 Cell culture}

A549 cell lines and H1299 cell lines were purchased from Type Culture Collection of the Chinese Academy of Sciences. Cell were cultured in high glucose DMEM containing 10\% FBS (sigma) and penicillin-streptomycin (100 units $/ \mathrm{ml}$, sigma) at $37^{\circ} \mathrm{C}$ with $5 \% \mathrm{CO} 2$. Melatonin and PD98059, a MEK inhibitor, were purchased from Cell Signaling Technology. Lentivirus for CDK4 overexpression or knockdown, and empty vector were purchased from Hanbio Biotechnology Co., Ltd. The infection of lentivirus was performed according to the protocol.

\subsection{Cell viability and colony formation}

Cell viability was performed by cell counting kit-8 (C0027, Beyotime Biotechnology). Cells were seeded into 96 -well plate and cultured at $37^{\circ} \mathrm{C}$ for $24 \mathrm{~h}$. Different concentration of melatonin $(0-4 \mathrm{mM})$ were 
treated when cells reached a certain density (60-70\%). Each well was washed by PBS $24 \mathrm{~h}$ later and then $10 \mu$ l CCK-8 reagent was added. After incubation for $4 \mathrm{~h}$, optical density (OD) values at $450 \mathrm{~nm}$ was detected by automatic microplate reader (Thermo Fisher Scientific, US). For colony formation detection, cells were planted into 6 -well plate at the density of $1000 /$ well. After being treated with $0,0.5,1,2 \mathrm{mmol} / \mathrm{L}$ melatonin for 48 hours, cells were incubated in fresh medium without melatonin for another 12 days. The clones containing more than 50 cells were observed after fixation and crystal violet staining.

\subsection{Cell morphology observation}

Cell proliferative ability, cell size and morphology were observed through full-automatic imaging system (Celldiscover 7.0, Carl Zeiss, German) under different magnification after pretreated with 0, 0.5, 1, 2 $\mathrm{mmol} / \mathrm{L}$ melatonin for 24 .

\subsection{Western blotting}

Proteins were extracted by cell lysis buffer (P0013B, Beyotime Biotechnology) supplemented with Phenylmethanesulfonyl fluoride (ST506, P0013B). Proteins of different molecular weight were separated through process of electrophoresis on $10 \%$ or $15 \%$ SDS-PAGE, and transferred to PVDF membrane through process of transmembrane. Before incubating with primary antibodies against CDK4, PCNA, Bax, $\beta$-actin, ERK, p-ERK and GAPDH (Cell Signaling Technology) at $4^{\circ} \mathrm{C}$ overnight, membranes were blocked with $5 \%$ skimmed milk in TBST for 2 hours to avoid non-specific binding. After incubating with secondary antibody (HRP-linked anti-lgG) for 2 hours at room temperature, ECL detection reagent (Thermo Fisher Scientific, US) was added on the band

\subsection{Quantitative real-time PCR}

RNA was extracted by Trizol reagent (Thermo Fisher Scientific, US). The primer sequences were listed: PCNA forward GAAGGTGTTGGAGGCACTCAAGG, reverse GCAGCGGTAGGTGTCGAAGC; CDK4 forward AGTTCGTGAGGTGGCTTTA, reverse GGGTGCCTTGTCCAGATA; Bax forward GATGCGTCCACCAAGAAGCTGAG, reverse GATGCGTCCACCAAGAAGCTGAG; $\beta$-actin forward CCTGGCACCCAGCACAAT, reverse GATGCGTCCACCAAGAAGCTGAG. The reagent of reverse transcription and PCR was conducted according with instructions (Takara Biotechnology, Dalian, China).

\subsection{Flow cytometry}

To detect cell cycle distribution, cells were harvested for 24 hours to be synchronized. After melatonin treatment for 24 hours, cells were resuspended in $75 \%$ ethanol for fixation at $4^{\circ} \mathrm{C}$ overnight. $500 \mu$ l binding buffer mixed with $25 \mu \mathrm{l}$ of $\mathrm{PI}$ and $10 \mu \mathrm{l}$ of RNaseA (C1052, Beyotime Biotechnology) at $37^{\circ} \mathrm{C}$ in darkness for 30 minutes was applied before detection. To detect apoptosis rate, cells were resuspended and stained by $500 \mu \mathrm{L}$ binding buffer mixed with $10 \mathrm{ul}$ of PI and 5ul of Annexin V-FITC (C1062M, Beyotime Biotechnology) at $20-25^{\circ} \mathrm{Cfor} 20$ minutes. Detection were conducted on CytoFLEX Flow Cytometer (Beckman Coulter, US).

\subsection{TUNEL assay}


The apoptosis cells were observed by TUNEL technique (C1090, Beyotime Biotechnology). Representative images were taken by laser scanning confocal microscope (LSM880, Carl Zeiss, German).

\subsection{Immunofluorescence staining}

After normal fixation, permeabilization and blocking, coverlips were incubated with primary antibody against CDK4 at $4{ }^{\circ} \mathrm{C}$ overnight. Afterwards, fluorescein isothiocyanate-conjugated secondary antibody incubation at $37^{\circ} \mathrm{C}$ for 30 minutes and DAPI staining for 5 minutes were performed. Images were captured by laser scanning confocal microscope (LSM880, Carl Zeiss, German).

\subsection{Immunohistochemistry}

After be deparaffinezed, rehydrated and antigen recovered, cutting slices were blocked by $1 \%$ albumin before incubated with primary antibody against CDK4 at $4{ }^{\circ} \mathrm{C}$ overnight. Then, slices were stabilized at room temperature for 30 minutes, and received secondary antibody incubation at $37^{\circ} \mathrm{C}$ for 30 minutes. Finally, the slides received DAB staining for 10 minutes and hematoxylin counterstaining for 5 minutes before taking pictures.

\subsection{Animal models}

BALB/c nude mice of 3-week-old were purchased from Shanghai Southern Model Biotechnology Co., Ltd. $6 \times 10^{6}$ A549 cells with or without CDK4 overexpression were subcutaneously injected into the right abdomen of mice. All mice developed subcutaneous tumor 7 days later and assigned to four groups: control, CDK4 overepxression (LV), $40 \mathrm{mg} / \mathrm{kg}$ melatonin, and LV+40 mg/ kg melatonin group. Mice underwent intraperitoneal injection of melatonin solution every 2 days. The length and width of tumors as well as the mice weight were recorded every 3 days. All mice were executed with integrally removal of subcutaneous tumors for further experiment 42 days later. Tumor volume was culculated as follow: volume $=0.52 \times$ length $\times$ width ${ }^{2}$.

\subsection{Statistical analysis}

Data were presented as mean \pm standard deviation (SD) of three independent experiments. The comparison between groups was analyzed by t-test or one-way ANOVA with GraphPad Prism 9.0. Statistically significant was proved as ${ }^{\star} \mathrm{p}<0.05$, ${ }^{\star *} \mathrm{p}<0.01$ vs control group; ${ }^{\#} \mathrm{P}<0.05$ vs LV group or Sh group; ${ }^{\&} \mathrm{P}<0.05$ vs melatonin group.

\section{Results}

\subsection{Melatonin inhibited colony formation, cell viability, and accelerated cell apoptosis.}

The results showed that 24 hours of melatonin pretreatment reduced the ability of cell cloning dosedependently (Figure 1A). The results of CCK-8 showed melatonin decreased cell viability dose dependently, and $2 \mathrm{mmol} / \mathrm{L}$ of melatonin is the optimal concentration for further experiment (Figure 1B). Photographs of cell morphology showed that $2 \mathrm{mmol} / \mathrm{L}$ of melatonin caused obvious cell shrinkage and 
loss of cellular attachment, as well as inhibited cell proliferative rate (Figure 1C). Photographs of immunofluorescence staining showed that $2 \mathrm{mmol} / \mathrm{L}$ melatonin decreased the expression of CDK4 and showed cell shrinkage and lack of cellular adhesion(Figure 1D). Photographs of TUNEL assay showed higher proportion of cellular apoptosis in melatonin group rather than control group (Figure 1E). Therefore, it is suggested that melatonin inhibited NSCLC cell colony formation, cell viability, and accelerated apoptosis.

\subsection{Inhibition of MEK activation particapated in melatonin-induced downregulation of CDK4.}

Western blotting showed melatonin downregulated the level of proliferative proteins, CDK4 and PCNA, while upregulated the expression of apoptosis related protein, Bax (Figure 2A-D). qRT-PCR analysis showed the same trend as in western blotting (Figure 2E-G). Besides, melatonin decreased the phophorylation of ERK without altering the expression of total ERK (Figure $2 \mathrm{H}-\mathrm{K}$ ). We further found that a MEK inhibitor, PD98059, decreased the expression of CDK4 compared with control group. What's more, combination of PD98059 and melatonin sinificantly downregulated the expression of CDK4 compared with PD98059 and melatonin alone group (Figure 2J). Therefore, it is suggested that inhibition of MEK activation particapated in melatonin-induced downregulation of CDK4.

\subsection{Melatonin contributed to cell cycle arrest and apoptosis.}

More cell accumulated in $\mathrm{G} 1$ phase after melatonin treatment while less cell accumulated in S phase, suggesting that melatonin blocked G1-to-S transition (Figure 3A, C-E). The proportion of apoptotic cells was significantly higher after melatonin treatment, especially in the early stage of apoptosis (Figure 3B, F). Therefore, it is suggested that melatonin contributed to cell cycle arrest and apoptosis.

\subsection{CDK4 overexpression reversed anticancer actions of melatonin.}

To further explore whether CDK4 is involved anticancer activities of melatonin, cells were transfected by recombinant lentivirus for upregulation of CDK4. CDK4 overexpression promoted the ability of colony formation. Interestingly, CDK4 overexpression reversed melatonin-induced inhibition of colony formation (Figure 4A). CDK4 and PCNA expressed higher CDK4 overexpression group. Besides, melatonin-induced suppression of CDK4 and PCNA were reversed by CDK4 overexpression. In contrary, the expression of Bax expressed lower in CDK4 overexpression group. Melatonin-induced increase of Bax was reversed by CDK4 overexpression (Figure 4B-E). qRT-PCR results showed the same trend as western blotting (Figure 4F-H). Therefore, it is suggested that CDK4 overexpression reversed anticancer actions of melatonin.

\subsection{CDK4 knockdown enhanced the anticaner actions of melatonin.}

Cells were transfected by lentivirus for downregulation of CDK4. CDK4 knockdown inhibited the ability of colony formation. What' more, CDK4 knockdown enhanced melatonin-induced inhibition of colony formation (Figure 5A). CDK4 and PCNA expressed lower in CDK4 knockdown group. Besides, CDK4 and PCNA expressed the lowest in CDK4 knockdown and melatonin co-treatment group. On the contrary, Bax expressed higher in CDK4 knockdown group and expressed highest in CDK4 knockdown and melatonin 
co-treatment group (Figure 5B-E). qRT-PCR results showed the same trend as western blot (Figure 5F-H). Therefore, it is suggested that CDK4 knockdown enhanced anti-cancer actions of melatonin.

\subsection{CDK4 overexpression weakened melatonin-induced cell cycle arrest and apoptosis.}

Less cell accumulated in $\mathrm{G} 1$ phase while more cell accumulated in S phase in CDK4 overexpression group. Interestingly, CDK4 overexpression reversed melatonin-induced increase of cell proportion in G1 phase (Figure 6A, C-E). Besides, the proportion of apoptosis cells, especially in early stage, was much lower in CDK4 overexpression group. Moreover, CDK4 overexpression significantly weakened melatonininduced cell apoptosis (Figure 6B, F). Therefore, it is suggested that CDK4 overexpression reversed melatonin-induced cell cycle arrest and apoptosis.

\subsection{CDK4 knockdown enhanced melatonin-induced cell cycle arrest and apoptosis.}

More cell accumulated in $\mathrm{G} 1$ phase while less cell accumulated in S phase in CDK4 knockdown group. What's more, the maximum of cells distributed in G1 phase after CDK4 knockdown and melatonin cotreatment (Figure 7A, C-E). Cell apoptosis results showed that more cell distributed in apoptosis area in CDK4 knockdown group. Besides, the proportion of apoptotic cells is the highest after CDK4 knockdown and melatonin co-treatment (Figure 7B, F). Therefore, it is suggested that CDK4 knockdown enhanced melatonin-induced cell cycle arrest and apoptosis.

\subsection{CDK4 overexpression reversed tumor growth inhibition of melatonin in vivo.}

To further verify outcomes in vitro experiment, we established tumor model in BALB/C nude mice by subcutaneously injection of A549 cell suspension. All mice successfully formed subcutaneous tumors one week later. Tumor volume in CDK4 overexpression group was the largest while that in $40 \mathrm{mg} / \mathrm{kg}$ melatonin group was the smallest. Besides, CDK4 overexpression and melatonin co-treatment reversed the melatonin-induced inhibition of tumor growth (Figure 8A-C). However, the body weight of all nude mice in four groups had no significant difference (Figure 8D). Similarily, the result of western blotting showed that intraperitoneal injection of melatonin reduced CDK4 and PCNA level while raised Bax expression. Moreover, CDK4 overexpression weankened melatonin-induced decrease of CDK4 and PCNA as well as the increase of Bax (Figure 8E-H). Immunohistochemical assay also proved that introperitoneal of melatonin decreased the expression of CDK4 in tumor tissue (Figure 8I-J).Therefore, it is suggested that melatonin slowed down tumor growth, and CDK4 overexpression reversed melatonin induced inhibition of tumor growth in vivo.

\section{Discussion}

It has been reported that the suppression of melatonin production and secretion might increases the risk of mutiple cancers (Dauchy et al., 2014; Hansen et al., 2017; Touitou et al., 2017). Therefore, it is indicated that melatonin has potential to exert protective activities in cancers (Ma et al., 2016). Melatonin reportedly inhibits tumor cell growth and promotes tumor cell apoptosis (Borin et al., 2016; Yun et al., 
2014). Consistently, we found that melatonin dose-dependently weaken cell viability and the ability of colony formation. Melatonin led to cell shrinkage and loss of cell adhesion, indicating signs of cell apoptosis in the early stage. Besides, melatonin dose-dependently affected the expression of proliferative and apoptotic proteins. The activation of ERK is known to involve in the pathological process of malignant transformation of cells (Lin et al., 2020). We verified whether melatonin regulated ERK expression in NSCLC. We found that melatonin decreased the phosphorylation of phosporylation of ERK without altering total ERK expression. To further examine the role of ERK in ERK inhibitor downregulated the expression of CDK4 and participated in melatonin-induced downregulation of CDK4. Additionally, melatonin blocked G1-to-S transition and induced G1 phase arrest. Moreover, melatonin increased the proportion of apoptosis cells. These results put forward that melatonin exerts anticancer actions by downregulating CDK4 via MEK/ERK signaling pathway in NSCLC cells.

Our study found CDK4 expressed lower by melatonin treatment in NSCLC cells. CDK4 was found to be disrupted and elevated in tumor cells, and the suppression of CDK4 reversed tumorigenesis (Patnaik et al., 2016; Choi et al., 2012). The inhibition of tumor growth was observed in several cancers by orally taking an CDK4/ 6 inhibitor (Gelbert et al., 2014; Yadav et al., 2014). Consistently, the results verified that CDK4 knockdown reduced cell growth. The result of western blotting showed that CDK4 knockdown decreased the level of PCNA in vitro. Interestingly, melatonin and CDK4 knockdown co-treatment further inhibited the expression of PCNA compared with melatonin alone treatment. However, CDK4 overexpression reversed the anti-proliferative effect of melatonin. Bollard et al (Bollard et al., 2017) reported that CDK4 inhibition suppressed cell growth rate by blocking cell cycle transition. We also found that CDK4 knockdown led to the G1 phase arrest and blocked G1-to-S transition. Interestingly, more cells were accumulated in $\mathrm{G} 1$ phase in melatonin and CDK4 knockdown co-treatment group than melatonin alone group. However, CDK4 overexpression reversed the melatonin-induced cell accumulation. These results indicated CDK4 knockdown enhanced G1 phase arrest and blockage of G1-to-S transition of melatonin in NSCLC cells. Consistently, Lee (Lee et al., 2018) found that melatonin disturbed the progression of cell cycle through decreasing the level of cyclinD, cyclinE, CDK4 and CDK6.

Previous studies reported that CDK4 not only involves in cell proliferation, but also in abnormal apoptosis (Wang et al., 2017; Naz et al., 2018; Jansen et al., 2017). CDK4 inhibition contributed to an increase of apoptosis related proteins (Feng et al., 2019). Herein, CDK knockdown increased the expression of Bax in NSCLC cells. Melatonin and CDK knockdown co-treatment further increased Bax expression than melatonin alone treatment. Nevertheless, CDK4 overexpression reversed melatonin-induced upregulation of Bax. Thangavel et al (Thangavel et al., 2018) reported that CDK4 inhibition triggered wrinkled membranes and nucleus, and induced apoptotic response in NSCLC cells. In our study, CDK4 knockdown increased the proportion of apoptosis cells, especially in the early stage. Additionally, CDK4 knockdown and melatonin co-treatment group synergistically increased the proportion of apoptosis cell compared with melatonin alone group. Whereas, CDK4 overexpression reversed melatonin-induced cell apoptosis. These results indicated that CDK4 knockdown enhanced the promotion of cell apoptostis of melatonin in NSCLC cells. 
Recent researches found that mouse model with CDK4 deficiency showed more resistance to tumorigenesis of NSCLC (Puyol et al., 2010). Melatonin inhibited the expression of tumor proliferative proteins, as well as lowered the incidence of tumorigenesis (Sanchez et al., 2017). Our study also proved that downregulation of CDK4 and melatonin were protective factors for tumor growth in vivo. Intraperitoneal injection of melatonin slowed down subcutaneous tumor growth without influencing the physical condition of mice, such as body weight. However, CDK4 overexpression elevated tumor growth rate and expression of proliferative proteins, indicating that CDK4 paticipated in melatonin-induced inhibition of tumor growth in vivo. Consistently, Kozar et al (Kozar et al., 2004) put forward that CDKs were critically required for expansion of cancer cells, and inhibition of CDK4 obviously affected cell proliferation and tumor growth.

In conclusion, CDK4 activation is involved in NSCLC cell proliferation and tumor growth. Melatonin functioned as a potential CDK4 inhibitor, induced G1 cell cycle arrest, blocked G1-to-S transition, as a result, inhibited cell proliferation and accelerated cell apoptosis (Figure 9). This study indicated that targeting CDK4 inhibition and combining it with melatonin has protential to be strategic for NSCLC.

\section{Declarations}

\section{ACKNOWLEGEMTNES}

The study was funded by the Project of Hefei Independent Innovation Policy (No.J2018Y04). We would like to thank The Center of Scientific Research of Anhui Medical University for providing us with experimental equipments.

\section{CONFLICT OF INTEREST}

The authors declared no conflict of interest.

\section{ETHICAL APPROVAL}

Animal experiments were conducted in strict accordance with ethical principles, and with approval of the Biomedical and the Animal Ethics Committee of Anhui Medical University (LLSC20211061).

\section{AUTHOR CONTRIBUTIONS}

Conception: Guanghe Fei and Mengxi Zhou; Experiment performance and data analysis: Mengxi Zhou, Yueguo Wang; Manuscript original draft: Mengxi Zhou; Manuscript revisement: Guanghe Fei and Mengxi Zhou; Funding: Guanghe Fei;

\section{References}

1. Sung, H., Ferlay, J., Siegel, R. L., Laversanne, M., Soerjomataram, I., Jemal, A., et al. (2021). Global Cancer Statistics 2020: GLOBOCAN Estimates of Incidence and Mortality Worldwide for 36 Cancers 
in 185 Countries. CA: a cancer journal for clinicians. 71(3), 209-249.

https://doi.org/10.3322/caac. 21660

2. Lee, S. S., and Cheah, Y. K. (2019). The Interplay between MicroRNAs and Cellular Components of Tumour Microenvironment (TME) on Non-Small-Cell Lung Cancer (NSCLC) Progression. J Immunol Res. 2019, 3046379. https://doi.org/10.1155/2019/3046379

3. Chen, Z., Fillmore, C. M., Hammerman, P. S., Kim, C. F., and Wong, K. K. (2014). Non-small-cell lung cancers: a heterogeneous set of diseases. Nat Rev Cancer. 14(8), 535-546. https://doi.org/10.1038/nrc3775

4. Ma, Z., Liu, D., Di, S., Zhang, Z., Li, W., Zhang, J., et al. (2019). Histone deacetylase 9 downregulation decreases tumor growth and promotes apoptosis in non-small cell lung cancer after melatonin treatment. J Pineal Res. 67(2), e12587. https://doi.org/10.1111/jpi.12587

5. Pourhanifeh, M. H., Sharifi, M., Reiter, R. J., Davoodabadi, A., and Asemi, Z. (2019). Melatonin and non-small cell lung cancer: new insights into signaling pathways. Cancer cell Int. 19, 131. https://doi.org/10.1186/s12935-019-0853-7

6. Hardeland, R., Cardinali, D. P., Srinivasan, V., Spence, D. W., Brown, G. M., and Pandi-Perumal, S. R. (2011). Melatonin-a pleiotropic, orchestrating regulator molecule. Prog neurobiol. 93(3), 350-384. https://doi.org/10.1016/j.pneurobio.2010.12. 004

7. Tan, D. X., Manchester, L. C., Esteban-Zubero, E., Zhou, Z., and Reiter, R. J. (2015). Melatonin as a Potent and Inducible Endogenous Antioxidant: Synthesis and Metabolism. Molecules. 20(10), 1888618906. https://doi.org/10.3390/molecules 201018886

8. Papantoniou, K., Castaño-Vinyals, G., Espinosa, A., Aragonés, N., Pérez-Gómez, B., Ardanaz, E., et al. (2016). Breast cancer risk and night shift work in a case-control study in a Spanish population. Eur $\mathrm{J}$ epidemiol. 31(9), 867-878. https://doi.org/10.1007/s10654-015-0073-y

9. Sigurdardottir, L. G., Markt, S. C., Rider, J. R., Haneuse, S., Fall, K., Schernhammer, E. S., et al. (2015). Urinary melatonin levels, sleep disruption, and risk of prostate cancer in elderly men. Eur Urol. 67(2), 191-194. https://doi.org/10.1016/j.eururo.2014.07.008

10. Devore, E. E., Warner, E. T., Eliassen, A. H., Brown, S. B., Beck, A. H., Hankinson, S. E., and Schernhammer, E. S. (2017). Urinary Melatonin in Relation to Postmenopausal Breast Cancer Risk According to Melatonin 1 Receptor Status. Cancer Epidemiol Biomark Prev. 26(3), 413-419. https://doi.org/10.1158/1055-9965.EPI-16-0630

11. Basler, M., Jetter, A., Fink, D., Seifert, B., Kullak-Ublick, G. A., and Trojan, A. (2014). Urinary excretion of melatonin and association with breast cancer: meta-analysis and review of the literature. Breast care. 9(3), 182-187. https://doi.org/10.1159/000363426

12. Jablonska, K., Pula, B., Zemla, A., Owczarek, T., Wojnar, A., Rys, J., et al. (2013). Expression of melatonin receptor MT1 in cells of human invasive ductal breast carcinoma. J Pineal Res. 54(3), 334-345. https://doi.org/10.1111/jpi.12032

13. Hevia, D., González-Menéndez, P., Quiros-González, I., Miar, A., Rodríguez-García, A., Tan, D. X., et al. (2015). Melatonin uptake through glucose transporters: a new target for melatonin inhibition of 
cancer. J Pineal Res. 58(2), 234-250. https://doi.org/10.1111/jpi.12210

14. Plaimee, P., Weerapreeyakul, N., Barusrux, S., and Johns, N. P. (2015). Melatonin potentiates cisplatininduced apoptosis and cell cycle arrest in human lung adenocarcinoma cells. Cell prolif. 48(1), 67-77. https://doi.org/10.1111/cpr.12158

15. Kong, T., Xue, Y., Cencic, R., Zhu, X., Monast, A., Fu, Z., et al. (2019). elF4A Inhibitors Suppress CellCycle Feedback Response and Acquired Resistance to CDK4/6 Inhibition in Cancer. Mol Cancer Ther. 18(11), 2158-2170. https://doi.org/10.1158/1535-7163.MCT-19-0162

16. Thangavel, C., Boopathi, E., Liu, Y., McNair, C., Haber, A., Perepelyuk, M., et al. (2018). Therapeutic Challenge with a CDK 4/6 Inhibitor Induces an RB-Dependent SMAC-Mediated Apoptotic Response in Non-Small Cell Lung Cancer. Clin Cancer Res. 24(6), 1402-1414. https://doi.org/10.1158/10780432.CCR-17-2074

17. Feng, H., Ge, F., Du, L., Zhang, Z., and Liu, D. (2019). MiR-34b-3p represses cell proliferation, cell cycle progression and cell apoptosis in non-small-cell lung cancer (NSCLC) by targeting CDK4. J Cell Mol Med. 23(8), 5282-5291. https://doi.org/10.1111/jcmm.14404

18. Hydbring, P., Malumbres, M., and Sicinski, P. (2016). Non-canonical functions of cell cycle cyclins and cyclin-dependent kinases. Nat Rev Mol Cell Biol. 17(5), 280-292. https://doi.org/10.1038/nrm.2016.27

19. Sobhani, N., D'Angelo, A., Pittacolo, M., Roviello, G., Miccoli, A., Corona, S. P.et al. (2019). Updates on the CDK4/6 Inhibitory Strategy and Combinations in Breast Cancer. Cells. 8(4), 321. https://doi.org/10.3390/cells8040321

20. Dauchy, R. T., Xiang, S., Mao, L., Brimer, S., Wren, M. A., Yuan, L., et al. (2014). Circadian and melatonin disruption by exposure to light at night drives intrinsic resistance to tamoxifen therapy in breast cancer. Cancer Res. 74(15), 4099-4110. https://doi.org/10.1158/0008-5472.CAN-13-3156

21. Hansen J. (2017). Night Shift Work and Risk of Breast Cancer. Curr Environ Health Rep. 4(3), 325339. https://doi.org/10.1007/s40572-017-0155-y

22. Touitou, Y., Reinberg, A., and Touitou, D. (2017). Association between light at night, melatonin secretion, sleep deprivation, and the internal clock: Health impacts and mechanisms of circadian disruption. Life Sci. 173, 94-106. https://doi.org/10.1016/j.Ifs.2017.02.008

23. Ma, Z., Yang, Y., Fan, C., Han, J., Wang, D., Di, S., et al. (2016). Melatonin as a potential anticarcinogen for non-small-cell lung cancer. Oncotarget. 7(29), 46768-46784.

https://doi.org/10.18632/oncotarget.8776

24. Borin, T. F., Arbab, A. S., Gelaleti, G. B., Ferreira, L. C., Moschetta, M. G., Jardim-Perassi, B. V., et al. (2016). Melatonin decreases breast cancer metastasis by modulating Rho-associated kinase protein1 expression. J Pineal Res. 60(1), 3-15. https://doi.org/10.1111/jpi.12270

25. Yun, M., Kim, E. O., Lee, D., Kim, J. H., Kim, J., Lee, H., et al. (2014). Melatonin sensitizes H1975 nonsmall-cell lung cancer cells harboring a T790M-targeted epidermal growth factor receptor mutation to the tyrosine kinase inhibitor gefitinib. Cell Physiol Biochem. 34(3), 865-872. https://doi.org/10.1159/000366305 
26. Lin, P. H., Tung, Y. T., Chen, H. Y., Chiang, Y. F., Hong, H. C., Huang, K. C., et al. (2020). Melatonin activates cell death programs for the suppression of uterine leiomyoma cell proliferation. Journal of pineal research. 68(1), e12620. https://doi.org/10.1111/jpi.12620

27. Patnaik, A., Rosen, L. S., Tolaney, S. M., Tolcher, A. W., Goldman, J. W., Gandhi, L., et al. (2016). Efficacy and Safety of Abemaciclib, an Inhibitor of CDK4 and CDK6, for Patients with Breast Cancer, Non-Small Cell Lung Cancer, and Other Solid Tumors. Cancer Discov. 6(7), 740-753. https://doi.org/10.1158/2159-8290.CD-16-0095

28. Choi, Y. J., Li, X., Hydbring, P., Sanda, T., Stefano, J., Christie, A. L., et al. (2012). The requirement for cyclin D function in tumor maintenance. Cancer Cell. 22(4), 438-451. https://doi.org/10.1016/j.ccr.2012.09.015

29. Gelbert, L. M., Cai, S., Lin, X., Sanchez-Martinez, C., Del Prado, M., Lallena, M. J., et al. (2014). Preclinical characterization of the CDK4/6 inhibitor LY2835219: in-vivo cell cycledependent/independent anti-tumor activities alone/in combination with gemcitabine. Invest New Drugs. 32(5), 825-837. https://doi.org/10.1007/s10637-014-0120-7

30. Yadav, V., Burke, T. F., Huber, L., Van Horn, R. D., Zhang, Y., Buchanan, S. G., et al. (2014). The CDK4/6 inhibitor LY2835219 overcomes vemurafenib resistance resulting from MAPK reactivation and cyclin D1 upregulation. Mol Cancer Ther. 13(10), 2253-2263. https://doi.org/10.1158/1535-7163.MCT-140257

31. Bollard, J., Miguela, V., Ruiz de Galarreta, M., Venkatesh, A., Bian, C. B., Roberto, M. P., et al. (2017). Palbociclib (PD-0332991), a selective CDK4/6 inhibitor, restricts tumour growth in preclinical models of hepatocellular carcinoma. Gut. 66(7), 1286-1296. https://doi.org/10.1136/gutjnl-2016-312268

32. Lee, H., Lee, H. J., Jung, J. H., Shin, E. A., and Kim, S. H. (2018). Melatonin disturbs SUMOylationmediated crosstalk between c-Myc and nestin via MT1 activation and promotes the sensitivity of paclitaxel in brain cancer stem cells. J Pineal Res. 65(2), e12496. https://doi.org/10.1111/jpi.12496

33. Wang, L., Zhang, R., You, X., Zhang, H., Wei, S., Cheng, T., et al. (2017). The steady-state level of CDK4 protein is regulated by antagonistic actions between PAQR4 and SKP2 and involved in tumorigenesis. JJ Mol Cell Biol. 9(5), 409-421. https://doi.org/10.1093/jmcb/mjx028

34. Naz, S., Sowers, A., Choudhuri, R., Wissler, M., Gamson, J., Mathias, A., et al. (2018). Abemaciclib, a Selective CDK4/6 Inhibitor, Enhances the Radiosensitivity of Non-Small Cell Lung Cancer In Vitro and In Vivo. Clin Cancer Res. 24(16), 3994-4005. https://doi.org/10.1158/1078-0432.CCR-17-3575

35. Jansen, V. M., Bhola, N. E., Bauer, J. A., Formisano, L., Lee, K. M., Hutchinson, K. E., et al. (2017). Kinome-Wide RNA Interference Screen Reveals a Role for PDK1 in Acquired Resistance to CDK4/6 Inhibition in ER-Positive Breast Cancer. Cancer Res. 77(9), 2488-2499. https://doi.org/10.1158/00085472.CAN-16-2653

36. Puyol, M., Martín, A., Dubus, P., Mulero, F., Pizcueta, P., Khan, G., et al. (2010). A synthetic lethal interaction between $\mathrm{K}$-Ras oncogenes and $\mathrm{Cdk} 4$ unveils a therapeutic strategy for non-small cell lung carcinoma. Cancer Cell. 18(1), 63-73. https://doi.org/10.1016/j.ccr.2010.05.025 
37. Sánchez, D. I., González-Fernández, B., San-Miguel, B., de Urbina, J. O., Crespo, I., González-Gallego, J., et al. (2017). Melatonin prevents deregulation of the sphingosine kinase/sphingosine 1-phosphate signaling pathway in a mouse model of diethylnitrosamine-induced hepatocellular carcinoma. $J$ Pineal Res. 62(1), 10.1111/jpi.12369. https://doi.org/10.1111/jpi.12369

38. Kozar, K., Ciemerych, M. A., Rebel, V. I., Shigematsu, H., Zagozdzon, A., Sicinska, E., et al. (2004). Mouse development and cell proliferation in the absence of D-cyclins. Cell. 118(4), 477-491. https://doi.org/10.1016/j.cell.2004.07.025.

\section{Figures}



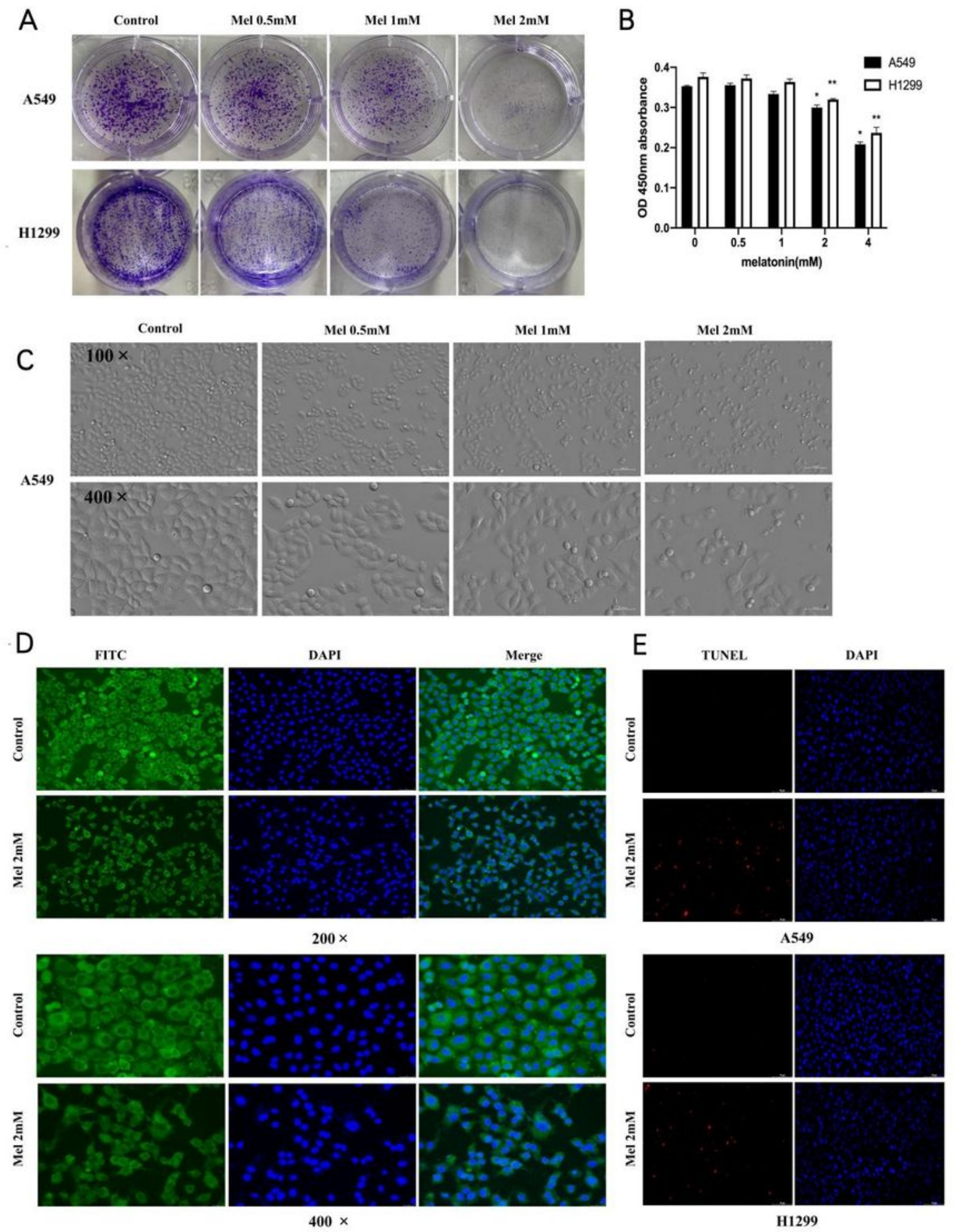

\section{Figure 1}

Melatonin inhibited colony formation, cell viability, and accelerated cell apoptosis. (A) The images of colony formation assay after melatonin treatment for $48 \mathrm{~h}$. (B) Cell viability tested by CCK-8 assay after melatonin treatment for 24 hours. (C) Images of cell morphology taken by automatic cell imaging system (magnification, 100x and 400x). (D) The expression of CDK4 and representative images of cell 
morphology performed by immunofluorescence and taken by laser scanning confocal microscope (magnification, 200x and 400x). (E) Images of apoptotic cell detected by TUNEL method.

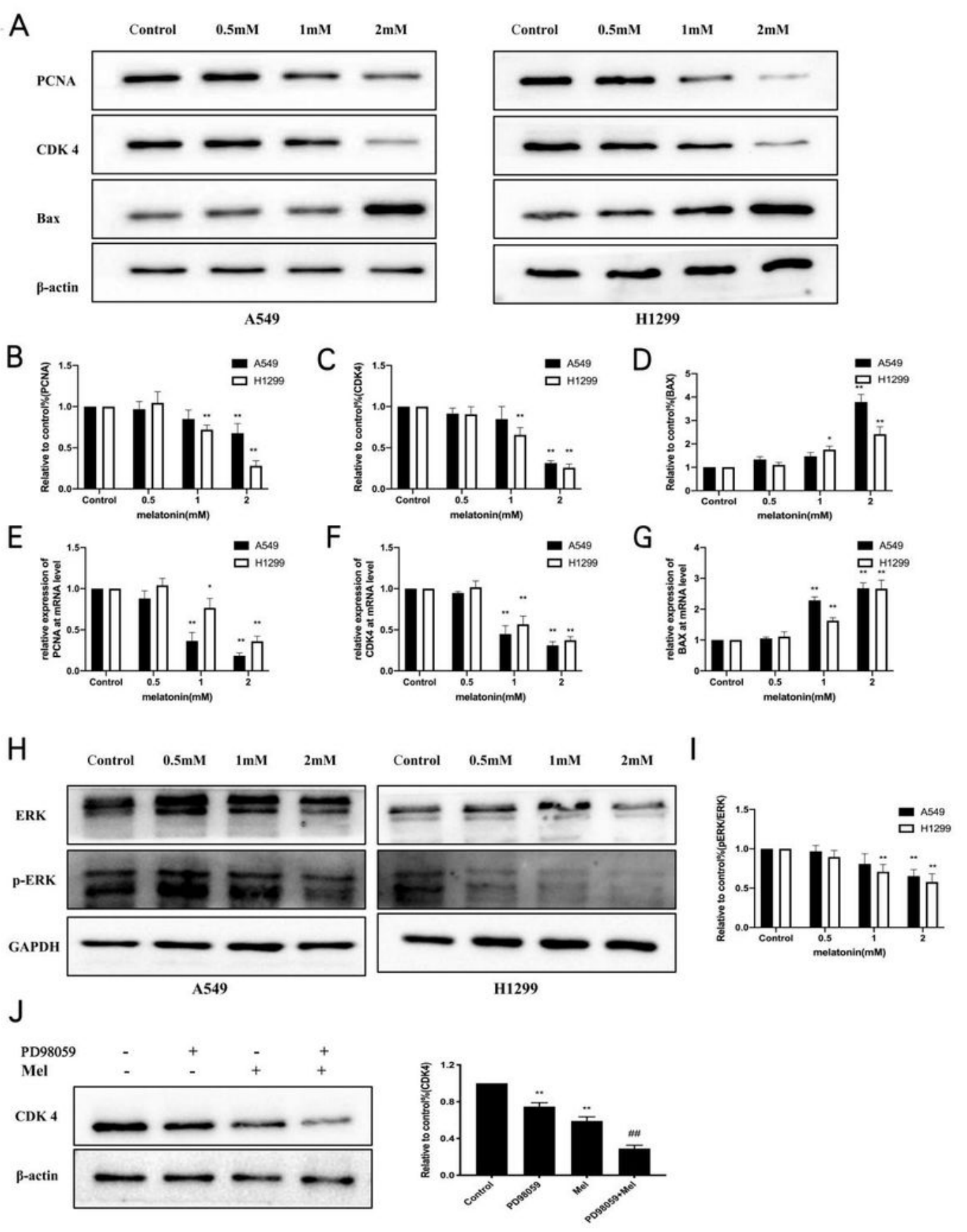

Figure 2

Inhibition of MEK activation particapated in melatonin-induced downregulation of CDK4.(A-D) Western blotting results of PCNA, CDK4 and Bax were detected after melatonin treatment. (E-G) The mRNA levels 
of PCNA, CDK4 and Bax measured by qRT-PCR after melatonin treatment. (H-I) Western blotting results of p-ERK, ERK were detected after melatonin treatment. $(\mathrm{J})$ Western blotting results of CDK4 were detected after PD98059 or melatonin treatment.
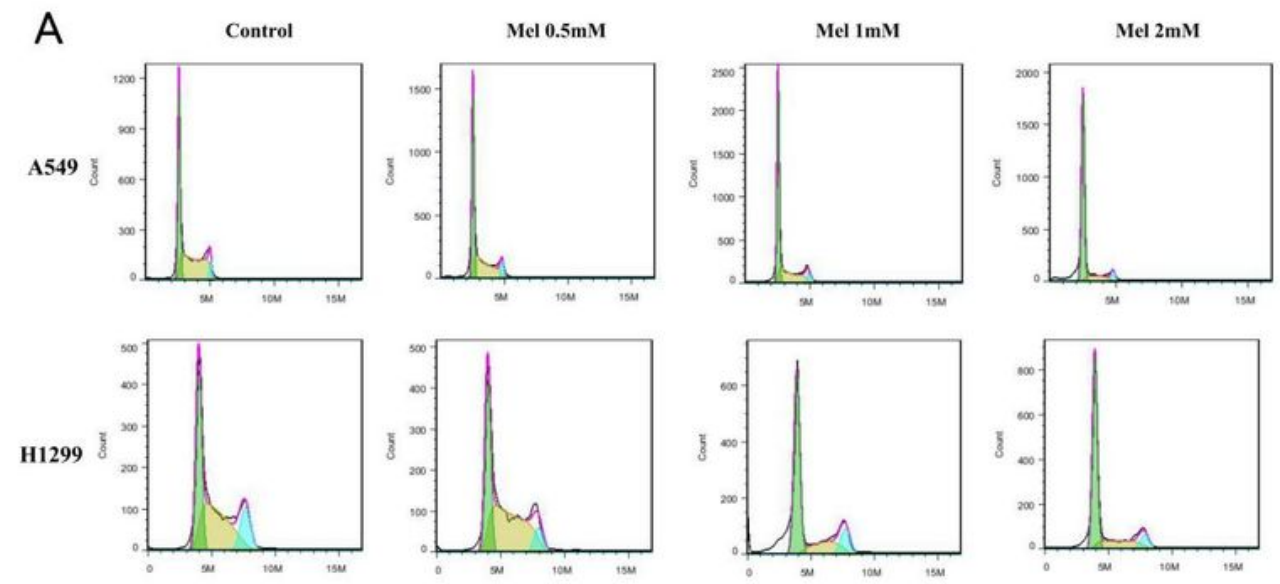

B
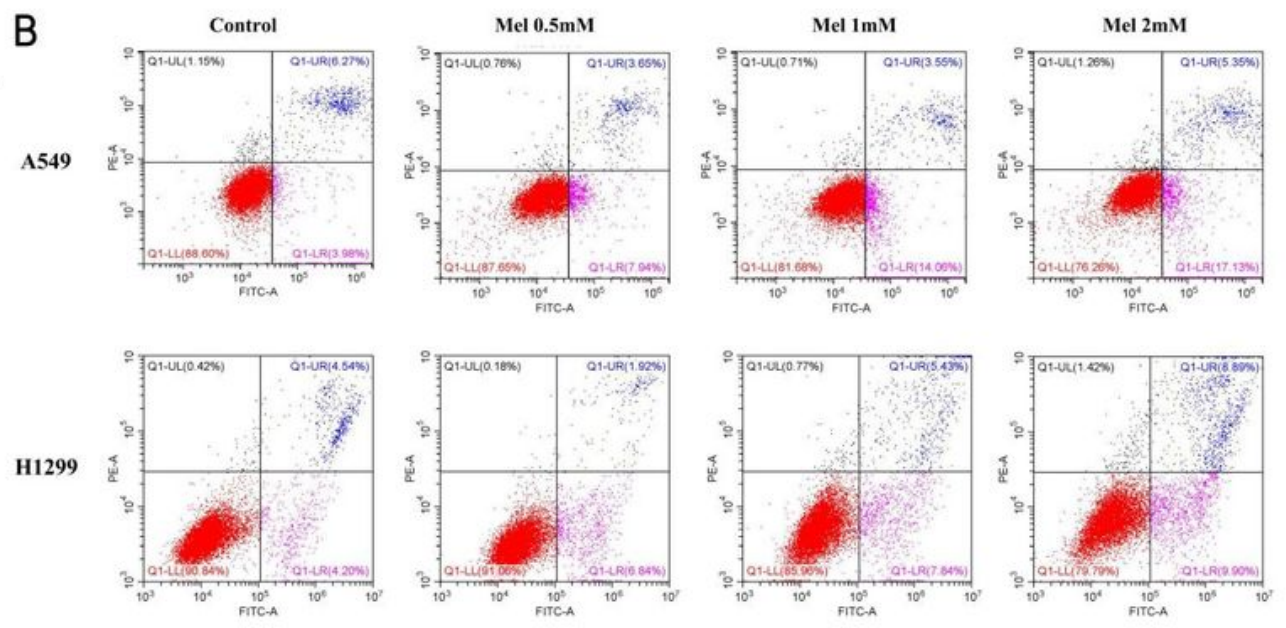

C
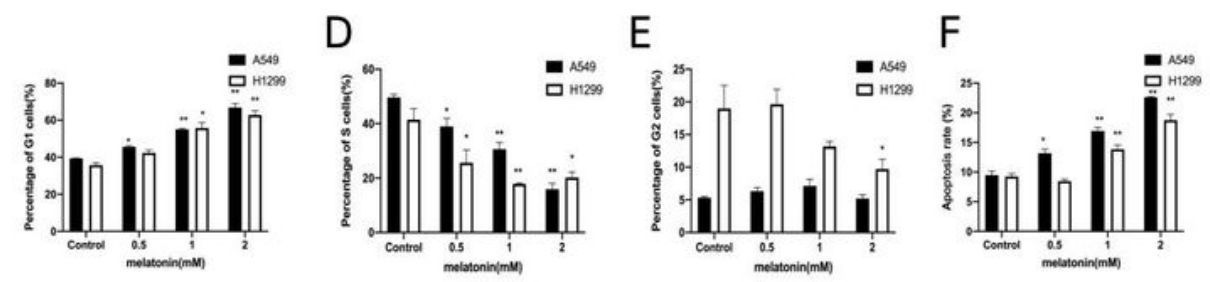

Figure 3 
Melatonin contributed to cell cycle arrest and apoptosis. (A, C-E) Cells with/without melatonin treatment were stained with $\mathrm{PI}$. The proportion of cells in different cell cycle phase were calculated by flow cytometry assay. (B, F) Cells with/without melatonin treatment were stained with Annexin V-FITC and PI. The proportion of cells in early and late apoptotic stage were calculated by flow cytometry assay.

A
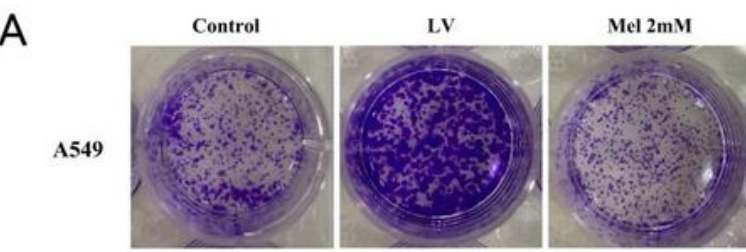

LV+Mel 2mM
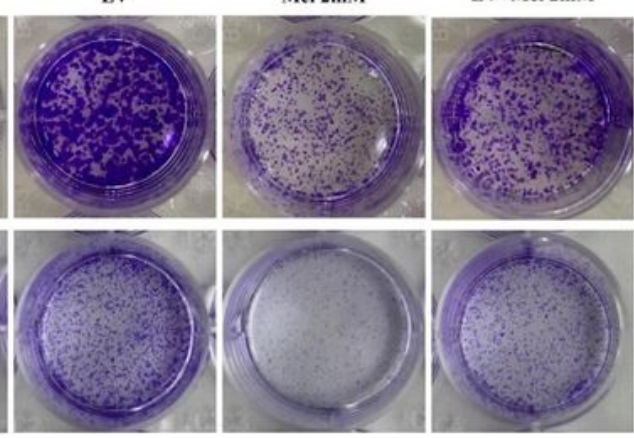

H1299
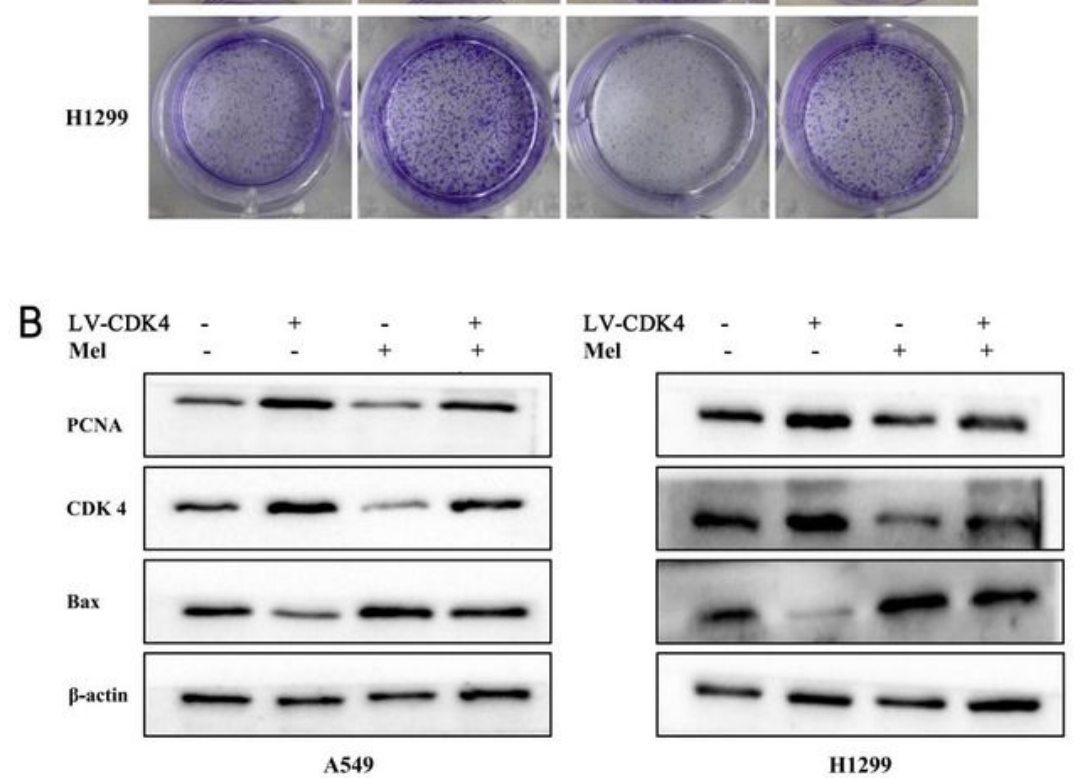

C

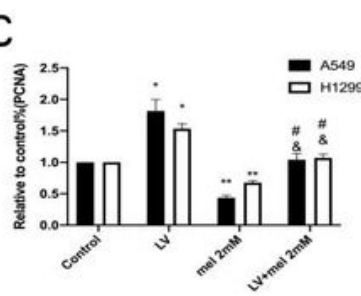

D $E$
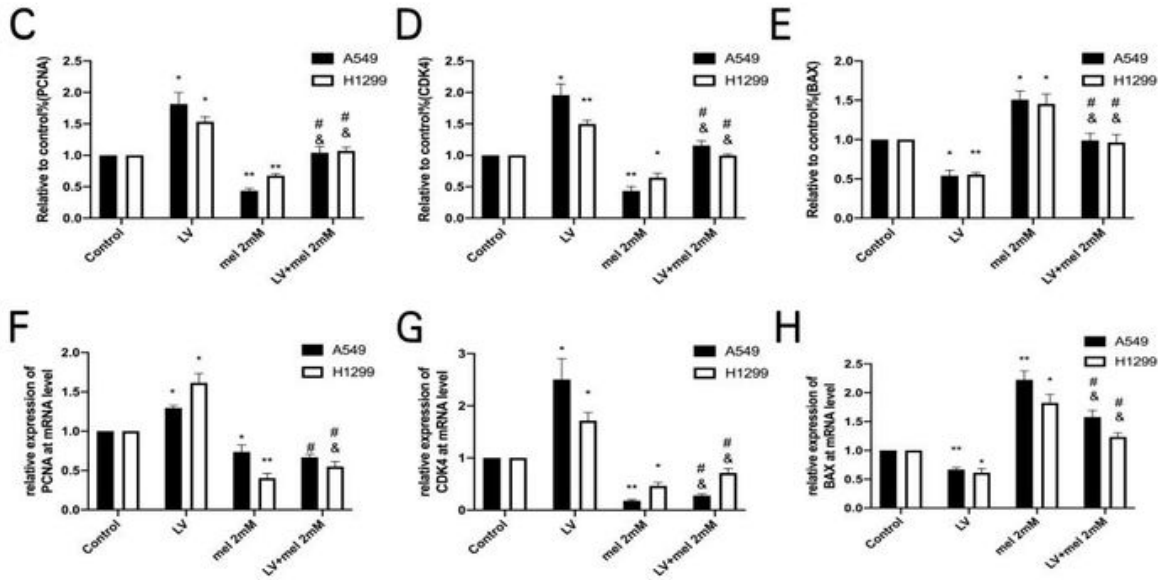

$\mathrm{H}$

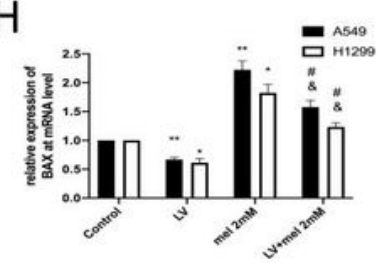

Figure 4 
CDK4 overexpression reversed anticancer actions of melatonin. (A) Cells were transfected with lentivirus for CDK4 overexpression. Images of colony formation assay were shown. (B-E) Western blotting results of PCNA, CDK4 and Bax were detected after different pretreatment. (F-H) The mRNA levels of PCNA, CDK4 and Bax detected by qRT-PCR after different pretreatment.

A
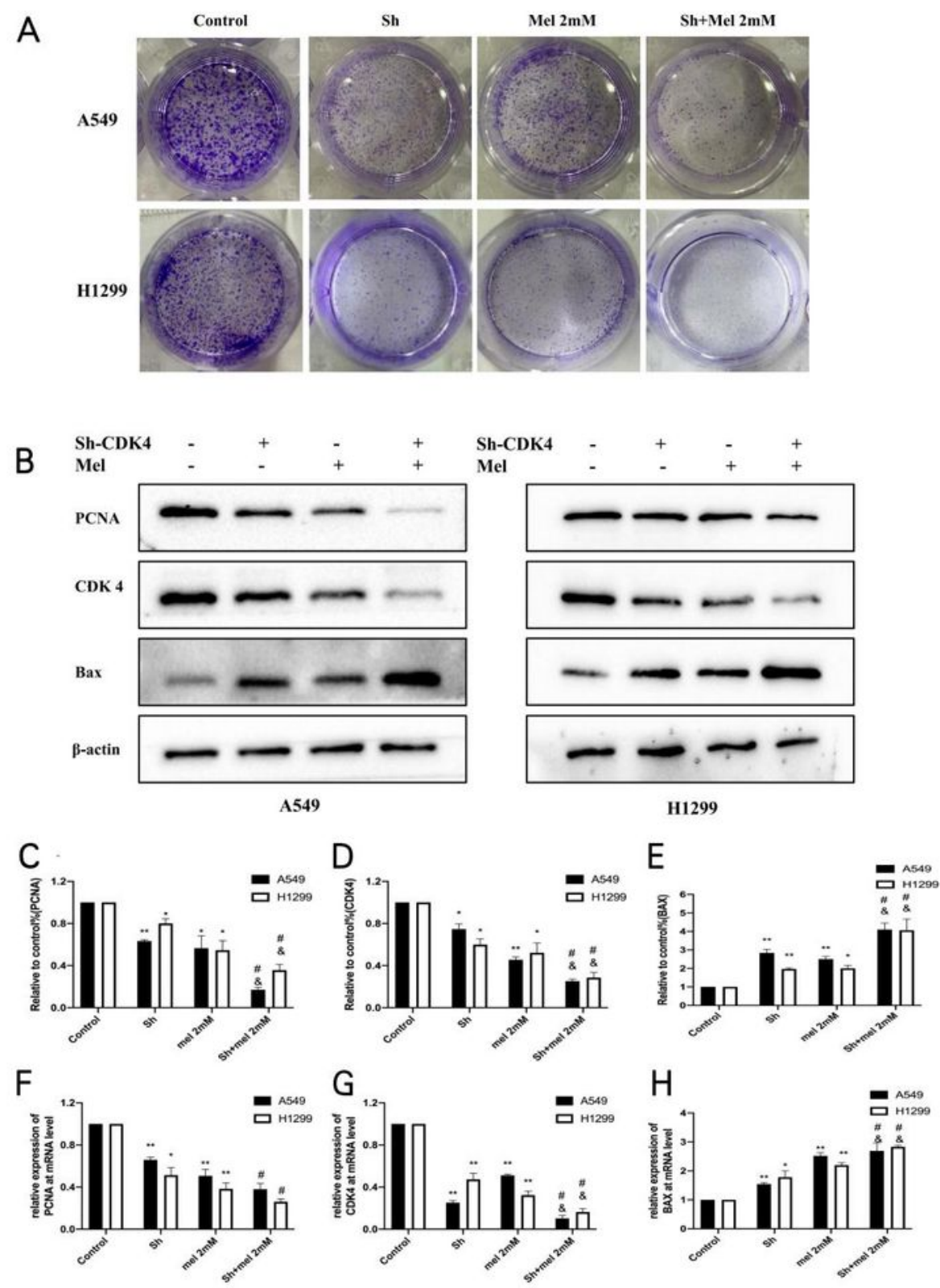

Figure 5 
CDK4 knockdown enhanced the anticaner actions of melatonin. (A) Cells were transfected with lentivirus for CDK4 knockdown. Images of colony formation assay were shown. (B-E) Western blotting results of PCNA, CDK4 and Bax were detected after different pretreatment. (F-H) The mRNA levels of PCNA, CDK4 and Bax detected by qRT-PCR after different pretreatment.

A
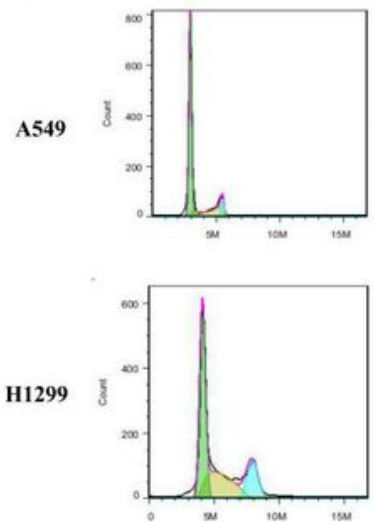

B
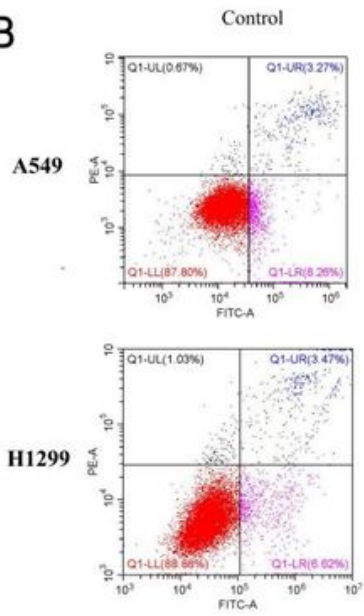

C

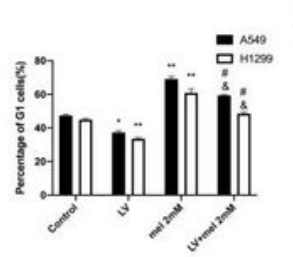

LV
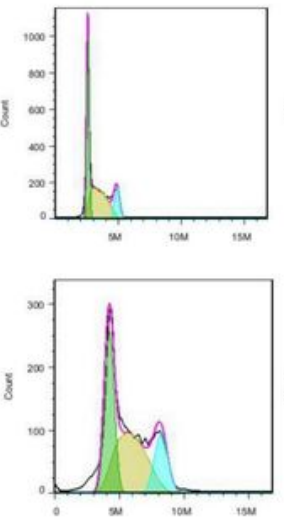

LV
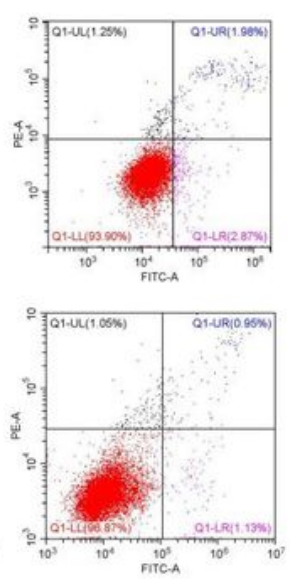

Mel $2 \mathrm{mM}$
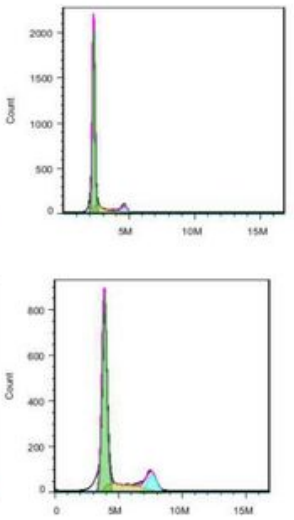

$\mathrm{Mel} 2 \mathrm{mM}$
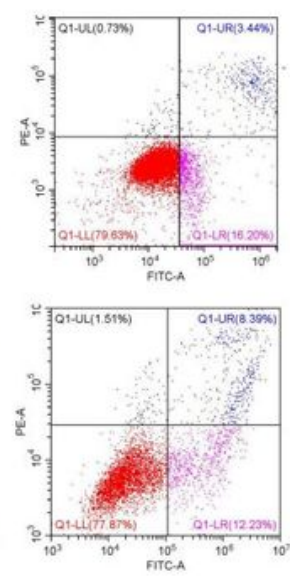

$\mathrm{LV}+\mathrm{Mel} 2 \mathrm{mM}$
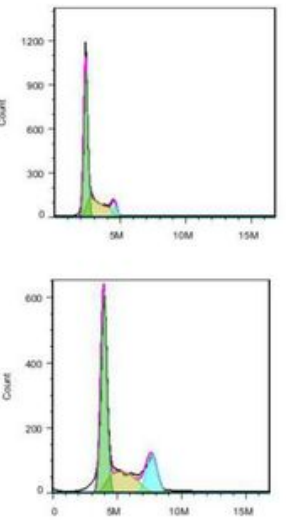

$\mathrm{LV}+\mathrm{Mel} 2 \mathrm{mM}$
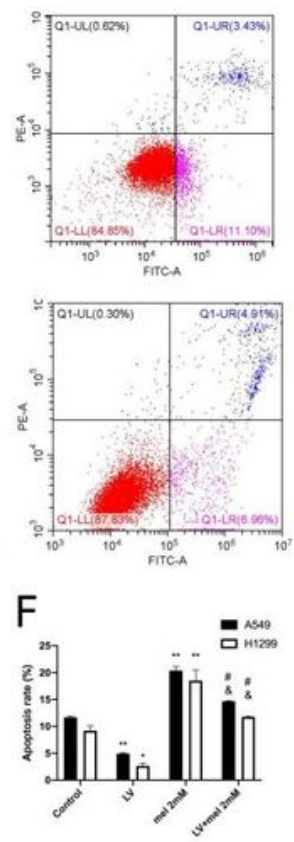

Figure 6 
CDK4 overexpression weakened melatonin-induced cell cycle arrest and apoptosis. (A, C-E) Cells were transfected with lentivirus for CDK4 overexpression. The distribution of cells in G1, $S$ and $\mathrm{G} 2$ cycle phase were calculated by flow cytometry. $(B, F)$ The proportion of apoptotic cells were calculated by flow cytometry.

A
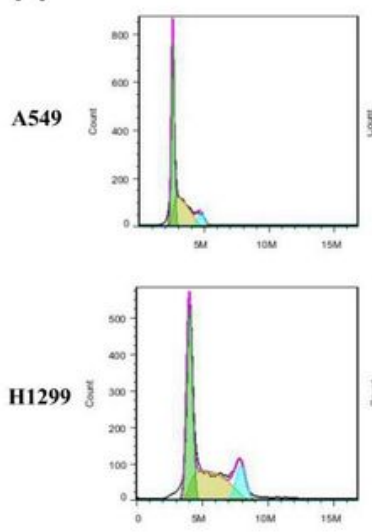

B
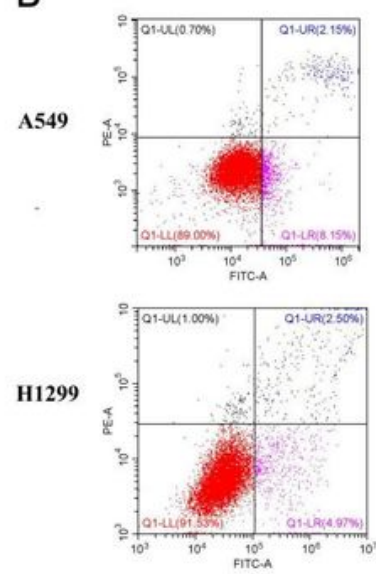

C

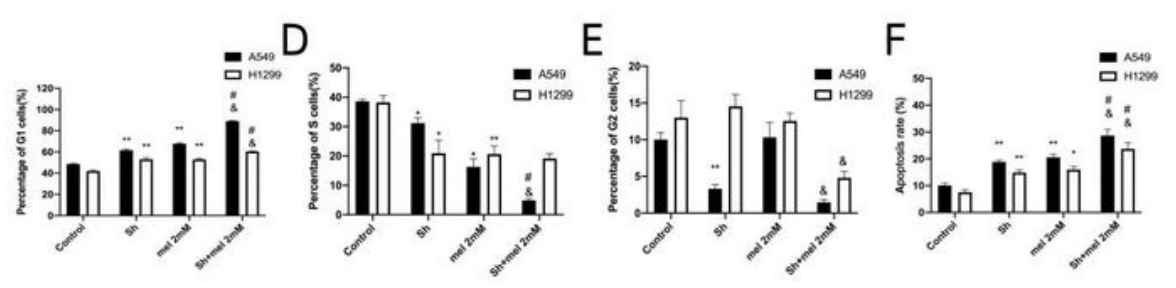

Sh
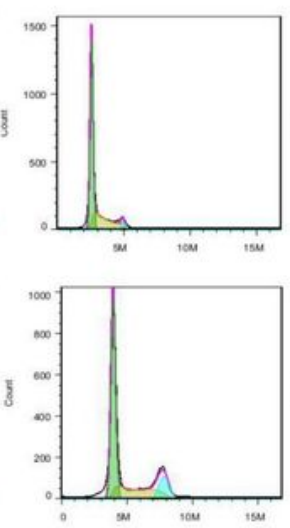

Sh
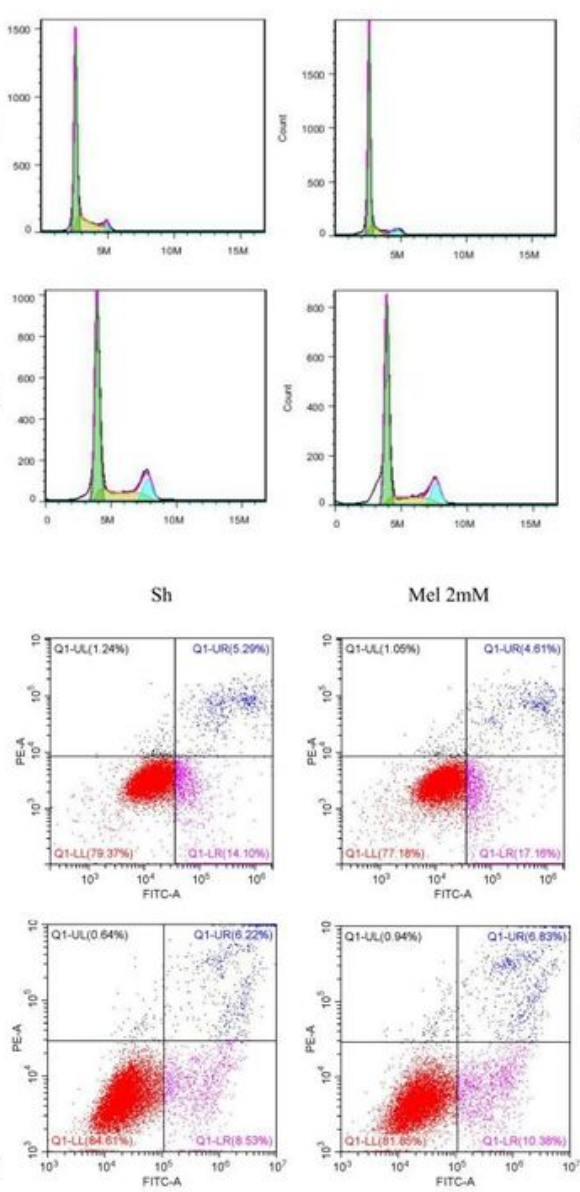

Mel $2 \mathrm{mM}$

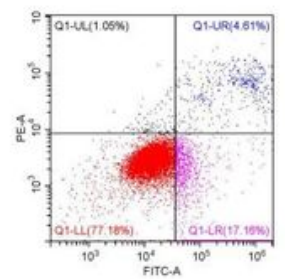

$\mathrm{Sh}+\mathrm{Mel} 2 \mathrm{mM}$
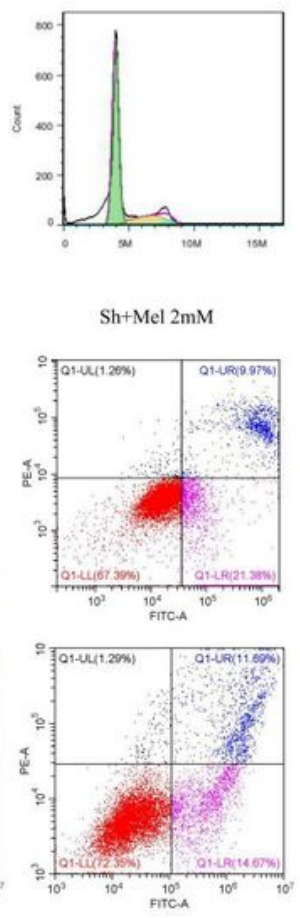

Sh+Mel $2 \mathrm{mM}$

Figure 7 
CDK4 knockdown enhanced melatonin-induced cell cycle arrest and apoptosis. (A, C-E) Cells were transfected with lentivirus for CDK4 knockdown. The distribution of cells in G1, S and G2 cell cycle phase were calculated by flow cytometry. (B, F) The proportion of apoptotic cells were calculated by flow cytometry.

A

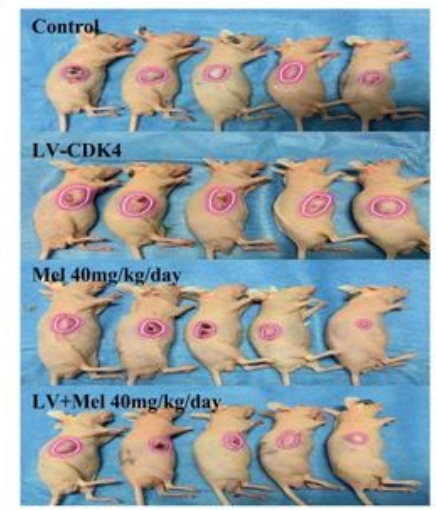

E

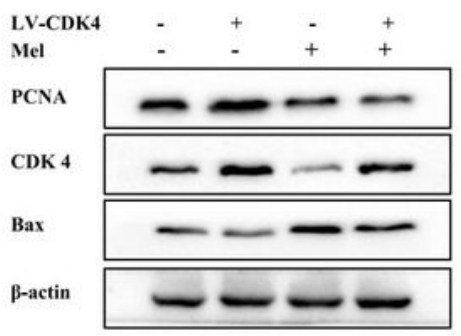

$\mathrm{F}$

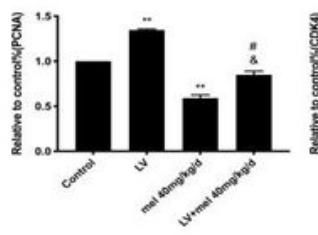

G

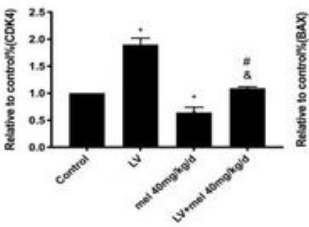

C

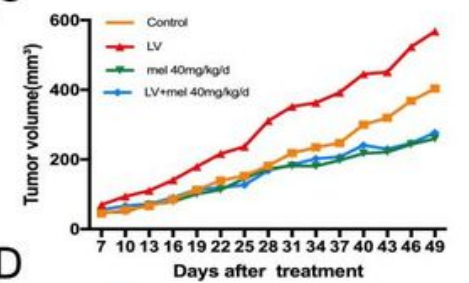

Days after treatment

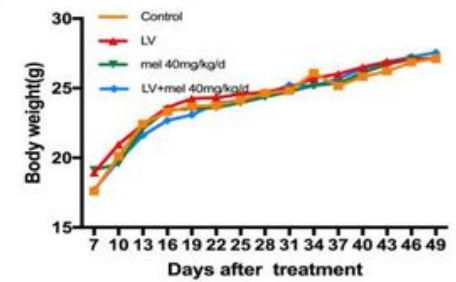

$\mathrm{H}$
I

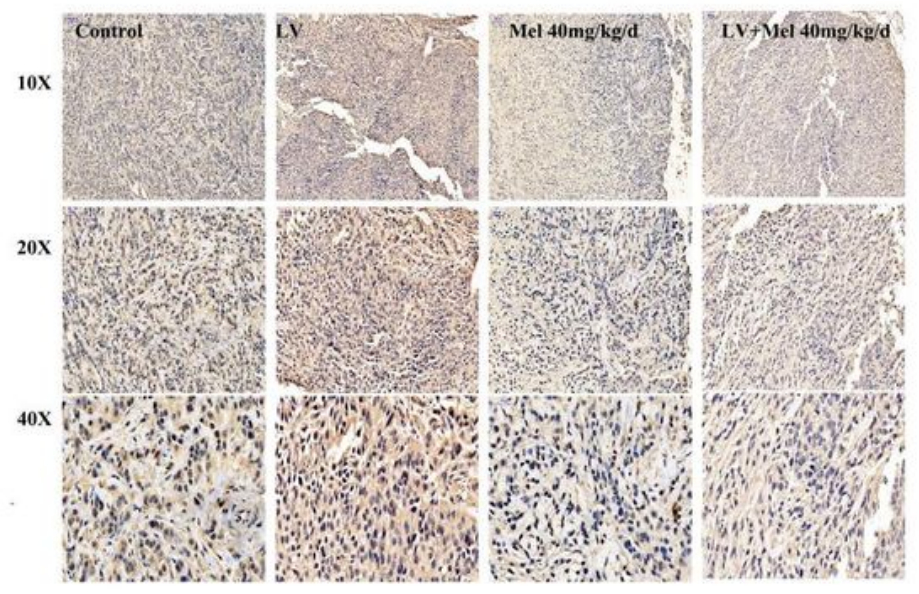

J

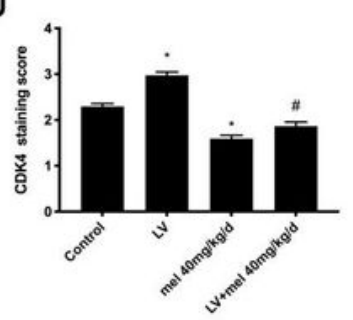

Figure 8 
CDK4 overexpression reversed tumor growth inhibition of melatonin in vivo. (A-B) Photographs of tumor morphology and volume in each group after different treatment. (C) The curve graphs of tumor volume in each group were drawn. (D) The curve graphs of body weight in each group were drawn. (E-H) The proteins extracted from tumor tissue were measured by western blotting. (I-J) The expression and location of CDK4 in tumor tissue were detected by immunohistochemistry (magnification, 10x, 20x and $40 \times)$.

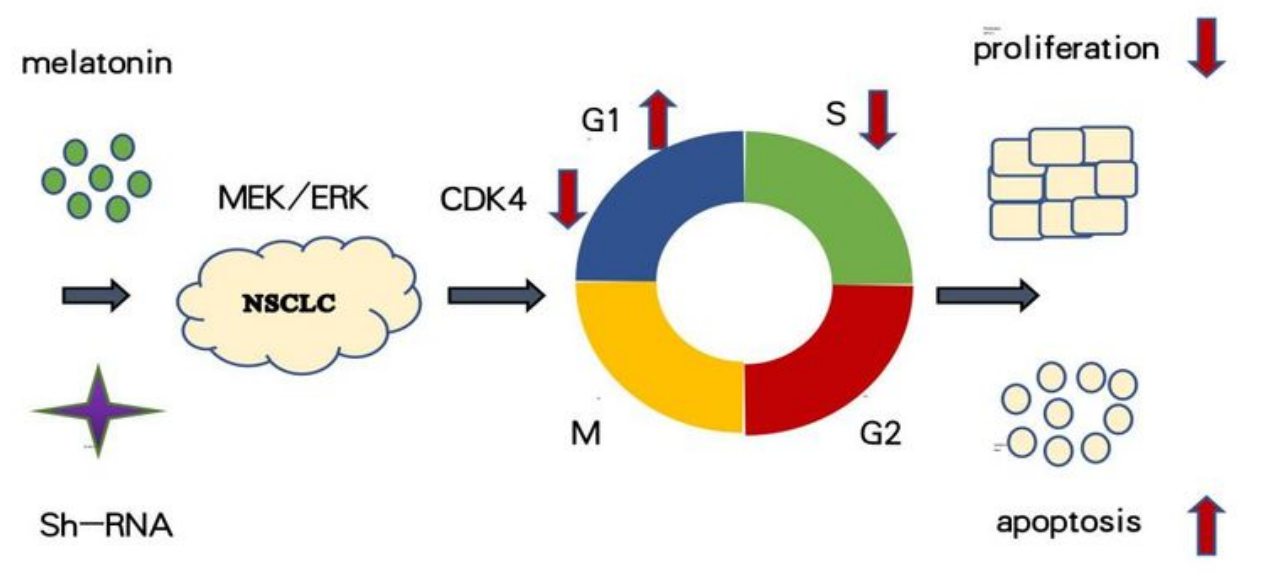




\section{Figure 9}

Schematic diagram about downregulation of CDK4 by melatonin via MEK/ERK pathway induced G1 cell cycle arrest, and then inhibited cell proliferation and accelerated apoptosis. 